\title{
SER 2020 - A COMPARATIVE APPROACH PROVING THE EU TANNING INDUSTRY'S CONTINUOUS STRIVING TOWARDS SUSTAINABLE DEVELOPMENT
}

\author{
GUSTAVO GONZALEZ-QUIJANO ${ }^{1}$, DOREL ACSINTE ${ }^{2,3}$, GHEORGHE BOSTACA ${ }^{2}$ \\ ${ }^{1}$ COTANCE, 40 Rue Washington, B-1050 Brussels, Belgium, cotance@euroleather.com \\ ${ }^{2}$ APPBR - Romanian Leather \& Fur Producers Association, 93 Ion Minulescu st., sector 3, \\ 031215, Bucharest, Romania, appb.ro@gmail.com \\ ${ }^{3}$ S.C. Pielorex S.A., Jilava, Bucharest
}

\begin{abstract}
The paper presents results of the new Social and Environmental Report of the European Leather Industry (SER 2020) that follows up on the exercise done in 2012. Based on an intensive survey amongst European tanneries, led by COTANCE and industriAll-European Trade Union, company data on social indicators and environmental parameters that reflect the performance of the tanning sector were collected. Companies' data, anonymised and aggregated at national level and centrally computed at European level are presented and analysed, versus 2012 data, where appropriate (in terms of average values). Social Footprint of the EU Tanning Industry (employment contracts, age distribution in the EU force, staff retention, education, citizenship, gender balance) and Environmental Footprint of the EU Tanning Industry (chemical consumption, energy consumption, breakdown of energy sources, water consumption, removal of water pollution, waste generation, solvent consumption, costs and investments) are thoroughly discussed. Finally, Sustainability priorities / Ethical issues for the value chain and Objectives and challenges for the future are communicated in order to demonstrate the continuous striving of Europe's leather sector towards excellence in social and environmental performance.
\end{abstract}

Keywords: social report; environmental footprint; sustainable development

\section{INTRODUCTION}

The peerless quality of European leather is internationally recognized. Technological innovation, process performance, environmental protection, social accountability, design and style, are the assets that make the success story of European tanners.

The European Tanning Industry is composed of nearly 1,600 companies and 33,000 workers and 7.4 billion Euro turnover, albeit there has been a gradual concentration over the last decade. The sector has traditionally been composed of family-owned small and medium enterprises but also includes large, listed multinational companies. The average size of a European tannery is currently 21 employees; in 2000, it was 24 employees. Today, the tanning industry in Europe represents a strategic segment of the manufacturing sector, thanks to the combination of tradition and continuous innovation. These characteristics have led the European tanning sector to become a global leader in terms of both value and of quality. The EU share of global turnover is the largest, at $30 \%$, before China, Brazil, India and the other producers.

European tanners process all the main species (bovine - over $80 \%$ of production -, ovine and caprine) and supply for all the end uses for leather. The main market destination of leather has traditionally been the footwear sector. It is still the largest destination, accounting for $38 \%$ of European production. However, in recent years use in other products has increased, such as leather goods $(22 \%)$ and car interiors (13\%). 
The Social and Environmental Report of the European Leather Industry (SER 2020) is the second publication of its kind. The first, published in 2013, was a follow-up action from a previous initiative of the Social Dialogue of the European Leather sector, that adopted a protocol for the reporting of social and environmental indicators. Indeed, as early as 2009 , business and workers representatives drew up a list of parameters against which to measure the sector's performance with regard to key social and environmental criteria. This was to help companies position themselves against a European benchmark, providing the sector with a common instrument for measuring progress over time, serving as a communication tool in the leather value chain, and as a model for other regions of the world.

This SER 2020 allows you to judge for yourself the commitment of the men and women of Europe's tanneries, to sustainability.

\section{WORKING METHOD APPROACHED}

Based on an intensive survey amongst European tanneries, led by COTANCE and industriAll-European Trade Union, company data on social indicators and environmental parameters that reflect the performance of the tanning sector were collected. Companies' data, anonymised and aggregated at national level and centrally computed at European level are presented and analysed, versus 2012 data, where appropriate (in terms of average values).

The sample comprised 79 companies (5\% of the EU total) from Italy, Germany, Austria, Denmark, Sweden, UK, Spain, France, Portugal, Hungary and Romania. Although the distribution of the respondents in the EU countries does not replicate the structure of the European tanning sector, the representativeness in terms of production volume is quite high at $43 \%$ of total EU production. Company data have been collected for each year of the reference period $(2016$ - 2017 - 2018).

To enable an assessment of trends between the first and second SER, the same Key Performance Indicators (KPIs) have been considered. They constitute the most significant parameters to assess sustainability. The comparison between SERs has been made on the basis of the average results of the first SER and the current one.

For the comparison of the results, it is worth noting that the samples of the two editions of the SER differ in terms of representativeness of company size, production cycle, leather typologies and countries of reference.

In particular, the 2019 survey is characterised by a higher percentage of full cycle companies (from hides/skins to finished leather). There were also differences between the reports, in terms of production specialization of the responding companies and their wastewater treatment options. Therefore, comparison of certain KPI was not done, due to the inconsistency of reporting between the two reports, e.g. waste production and removal of pollutants. Moreover, the different sample composition led to a slight increase of some environmental indicators (chemicals consumption, waste) due to inherent differences in the processes described, skewing the final result. For example, the second report included a higher proportion of full-cycle, high volume bovine leather manufacturers for the automotive sector which as previously noted, will report more process steps and consequently, greater use of chemicals and energy, artificially distorting any comparison with the first report. 


\section{RESULTS AND DISCUSSIONS}

\section{Social Footprint of the EU Tanning Industry}

One of the pillars on which the social responsibility of the European tanning industry is based is the respect and valorisation of human resources. This is essential for an industry that combines technological innovation and craftsmanship.

\section{Employment Contracts}

More than $90 \%$ of workers in European tanneries have a permanent employment contract. Breakdown of workers in the sample is presented in Figure 1.

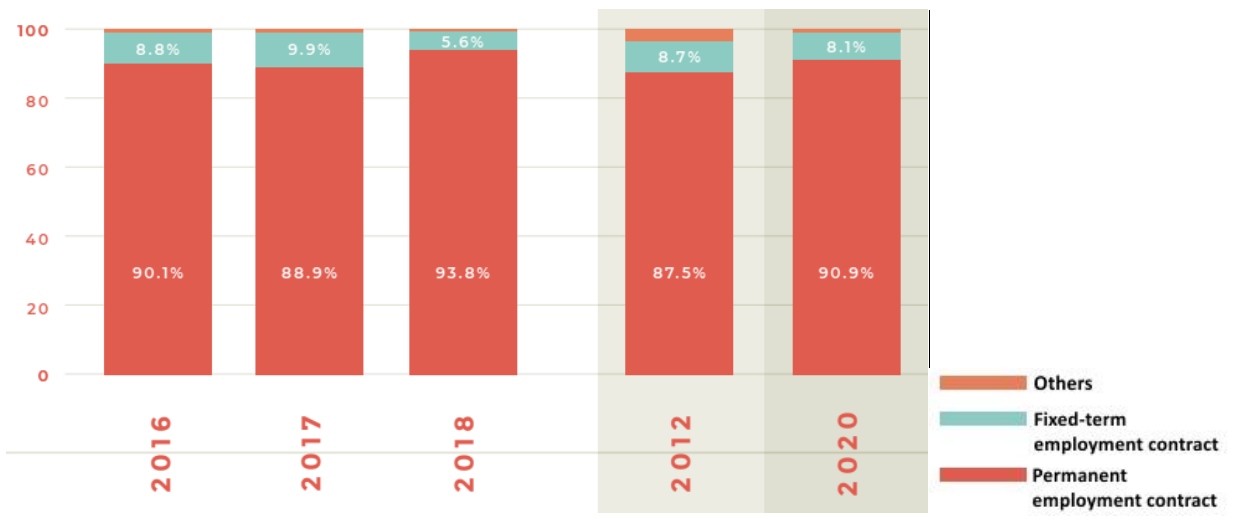

Figure 1. Breakdown of workers in the sample by employment contract, comparison SER 2012 vs. SER 2020

\section{Age Distribution in the EU Workforce}

The age distribution data revealed an increase in the over 55 age group and a decrease in the 36-45 age group. Age brackets are presented in Figure 2.

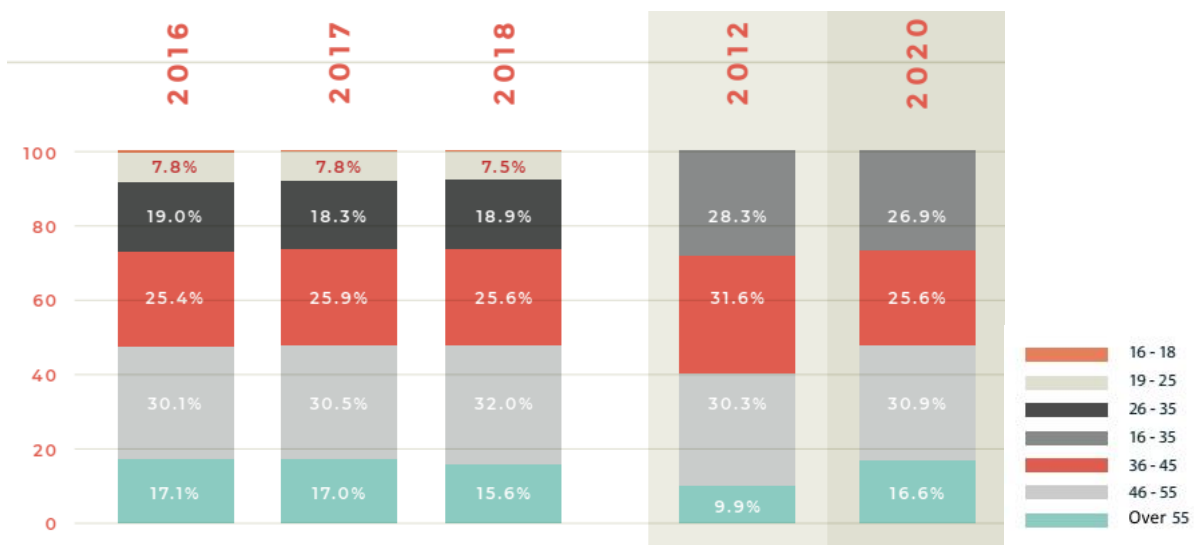

Figure 2. Age distribution of workers in the tanneries composing the sample, comparison SER 2012 vs. SER 2020 


\section{Staff Retention}

The data confirm that almost $50 \%$ of the workforce has been employed in the tanning sector for more than 10 years, 26\% from 10 to 20 years and $12 \%$ between 20 and 30 years. This confirms that employees recognise and value work in the tannery, which, despite its unwarranted negative image, is characterised by a safe and stimulating working environment.

\section{Education}

The education data reveals a more educated workforce than seen in 2012. The number of employees with qualifications of EQF $5 \& 6$ has doubled and those with EQF $3 \& 4$ has also increased, compared to 2012.

\section{Citizenship}

The number of migrant workers has doubled since the previous survey. This is linked to the increased mobility of workers in the sector in EU countries, especially in Central and Northern Europe, in the last year.

\section{Gender Balance}

The number of females in the workforce has increased slightly compared to 2012. The trend is certainly positive, although with the physical nature of tannery work, it is unlikely that gender balance will be achieved. The slight increase in female personnel could be linked to the ongoing process of transformation and technological innovation of manufacturing processes, which has reduced the very physical nature of some activities.

\section{Environmental Footprint of the EU Leather Industry}

Tanning is fundamentally an activity corresponding to the circular economy. The raw materials, hides and skins, are residues of the food industry, bio-based substances synthesized from by-products or residues of other industries are used in tanning processes, and residues from the leather process can be recovered and used by other industrial sectors, including agriculture, food, pharmaceutics and others. Finally, leather is a durable material. Leather articles will last a lifetime and can be repaired or remanufactured, going well beyond resource efficiency and recycling.

\section{Chemical Consumption}

Data collected for this survey show that between 2016 and 2018, European tanneries consumed an average $2.15 \mathrm{~kg}$ of chemicals per square metre of finished leather. Chemical products are normally applied in aqueous solution during the 'wet processes' of leather manufacture (liming, tanning, dyeing and fatliquoring) and sprayed or layered on the surface of the leather during the finishing phase. Average consumption of chemicals $\left(\mathrm{kg} / \mathrm{m}^{2}\right)$ in the tanneries composing the sample, 2016-2018, are presented in Figure 3. 


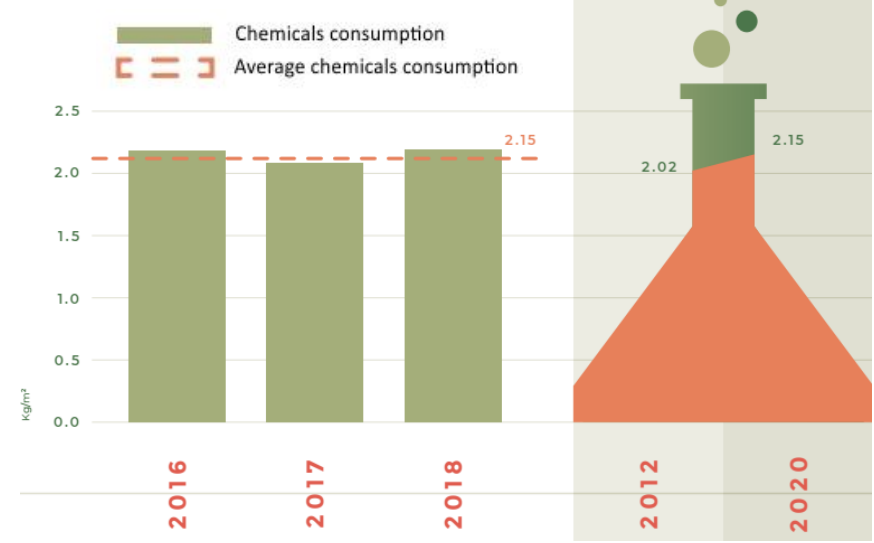

Figure 3. Average consumption of chemicals $\left(\mathrm{kg} / \mathrm{m}^{2}\right)$ in the tanneries composing the sample, comparison SER 2012 vs. SER 2020

Note: Differences in the sample composition in 2012 and 2020 do not allow a meaningful direct comparison. In 2012 there was a significantly higher proportion of tanneries starting from wet-blue which results in an average lower chemicals consumption. The closeness to the 2020 figure suggests that there has been a further reduction in chemical consumption.

\section{Energy Consumption}

Over the last three years, European tanners used an average of 1.76 Tonne of Oil Equivalent (TOE) per 1000 square metres of leather. This unit represents the amount of energy released by burning one tonne of crude oil, about 42 gigajoules or 11630 megawatt-hours. Average consumption of energy by tanneries composing the sample expressed in terms of Tonnes of Oil Equivalent (TOE) per $\mathrm{m}^{2}, 2016-2018$, is presented in Figure 4.

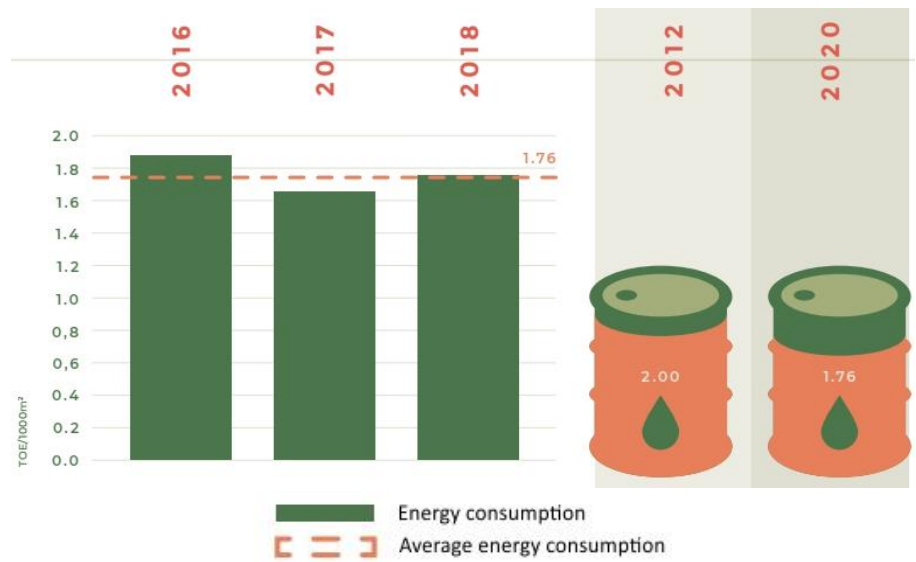

Figure 4. Comparison of the average consumption of energy expressed in terms of Tonnes of Oil Equivalent (TOE) per $\mathrm{m}^{2}$ by tanneries composing the sample of SER 2012 and SER 2020 
SER 2020 - A Comparative Approach Proving the EU Tanning Industry's Continuous Striving towards Sustainable Development

\section{Breakdown of Energy Sources}

Natural gas is the main source of energy for European tanneries, accounting for more than $2 / 3$ of total energy consumption. However, tanneries are investing more and more in renewable energy resources.

\section{Water Consumption}

In 2016-2018, European tanneries consumed an average of 0.121 cubic metres of water to produce one square metre of finished leather, about $7 \%$ less than the amount reported for years 2010-2011.

\section{Removal of Water Pollution}

Efficiency of wastewater treatments with regard to certain pollutants for the tanneries composing the sample, 2016-2018, is presented in Figure 5.

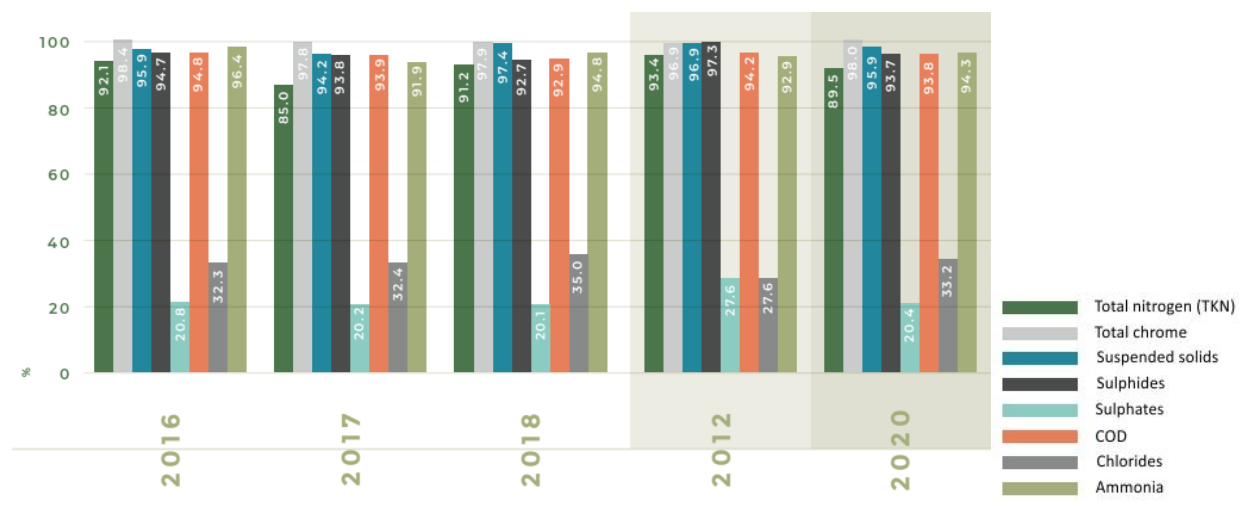

Figure 5. Efficiency of wastewater treatments with regard to certain pollutants for the tanneries composing the sample, comparison SER 2012 vs. SER 2020

\section{Waste Generation}

After valorisation of by-products, European tanneries generate an average of $2.63 \mathrm{~kg}$ of wastes per square metre of finished leather produced.

\section{Solvent Consumption}

In order to further reduce emissions to air, the European tanning sector is constantly working to reduce the use of solvents. As such, solvent consumption is a good measure for monitoring the quality of tannery air emissions. The 3-year analysis shows an average solvent consumption of $29.5 \mathrm{~g}$ per square metre of finished leather. This represents a reduction of $32 \%$ compared to the previous report.

\section{Environmental Costs and Investments}

Environmental costs in 2020 are similar to those reported in 2010, averaging around $4 \%$ of turnover. The value represents the "equilibrium level" between increased 
investments/costs and efficiency in processing (from both an environmental and economical perspective). The main directions are the following:

- Wastewater treatment

- Waste management

- Air pollution abatement

- $\quad$ Energy saving/renewable energy

\section{Sustainability Priorities / Ethical Issues for the Value Chain}

Mainly refer to:

- Fair trade (banning of export restrictions/ taxes on raw materials)

- Product quality and innovation

- Social accountability and environmental performance

- Due diligence: proactive and reactive process through which enterprises can prevent and mitigate adverse impacts related to human rights, labour rights, or the environment

- Product safety: refers to origin marking, requirements applicable to leather, process chemicals and auxiliaries for leather production

- Traceability and transparency in the supply chain

- Animal welfare

\section{Objectives and Challenges for the Future}

Important tasks for the future in our opinion seem to be:

- Protection of the term leather and guarantee the authenticity of leather in advertisements or labels and descriptions of articles and products, so that consumers can make informed purchasing choices.

- Quality of raw materials, that requires the alignment of all the links of the supply chain, from livestock breeding and transport, to slaughterhouses and hides \& skins collection and storage centres.

- Sectoral education \& training services: with an ageing population, it is important to ensure the renewal of the workforce and the transmission of knowledge as well as the provision of new skills.

- Strengthen the good governance of the sector at the international level.

\section{CONCLUSIONS}

Leather is a fascinating material in many ways. Who doesn't react to the distinctive scent of leather or the soft, warm touch of its surface? But leather invites our interest for other reasons. It is probably the oldest example of the circular economy.

Leather-making is also sensible from an ethical and environmental point of view. It is now widely understood that livestock are not slaughtered for hides or skins, as they represent only a small part of the value of an animal. The use of these raw materials is significantly better than wasting them, creating a global environmental and sanitary disaster.

The use of leather avoids the waste of a renewable resource. Using leather reduces the need for plastics or other synthetics derived from non-renewable sources, that end up in our oceans and whose micro-particles can now even be found in the food chain. 
Leather is also natural and biodegradable. However, to be deserving of the qualification of sustainable, leather must also comply with strict social and environmental standards. It is nonsensical for leather to have these extraordinary intrinsic credentials, if during its production it creates more environmental damage than it avoids, or if workers are exposed to dangerous chemicals. Just as leather must fulfil strict criteria for protection of consumers, emissions to water, land or air, risks during production must be also managed and reduced.

Europe's environmental ambitions are described in its Green Deal, the Circular Economy Action Plan and the Farm to Fork Strategy. The European Leather industry expects much from these. After the adoption of the PEFCR for leather, the industry is now advocating for zero-allocation of the environmental impact of livestock rearing to hides and skins, and participating in the development of a PEFCR for Apparel \& Footwear. In this context, $R \& D$ for cleaner production technologies continues to improve the sector's environmental performance while improving the quality of products and processes.

The Social and Environmental Report (SER 2020) illustrates all of these and the progress achieved by the European Leather Industry, since 2012, towards sustainable development.

\section{Acknowledgements}

COTANCE and IndustriAll - European Trade Union, the Social partners of the project VS/2019/0009, express their gratitude in particular to all European Leather Associations, companies and worker representatives that have offered their support and contribution to the development of all activities.

COTANCE and IndustriAll-Europe dedicate the Social \& Environmental Report (SER 2020) of the European Leather Industry to the sector's COVID-19 victims, their families and their communities.

\section{REFERENCES}

COTANCE (2020), Social and Environmental Report of the European Leather Industry, Social Dialogue Project VS/2019/0009, www.euroleather.com.

The European Commission support for the production of this publication The content is the sole responsibility of the authors and the Commission cannot be held responsible for any use which may be made of the information contained herein.

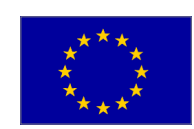

https://doi.org/10.24264/icams-2020.I.0 